\title{
The Use of Benzil to Obtain Functionalized $N$-Heterocycles
}

\author{
Mara E. F. Braibante,* Hugo T. S. Braibante, Marciana P. Uliana, \\ Carla C. Costa and Marcelo Spenazzatto
}

\author{
Departamento de Química, Universidade Federal de Santa Maria, 97105-900 Santa Maria-RS, Brazil
}

\begin{abstract}
Neste trabalho foi estudada a reatividade da benzila, empregando-se $C, N$ - e $N, N$-nucleófilos tais como 2-butenoatos de etila 3-amino substituidos 4a-c, (S,Z)-3-(1-etóxi-3-hidróxi-1-oxo-2propanilamina)-2-butenoato de etila $\mathbf{6}$, semicarbazida 8 e tiossemicarbazida 10, para avaliar os centros eletrofílicos na formação de compostos heterocíclicos polifuncionalizados, obtendo-se pirrolinonas 5a-c, pirrol 7, triazinona 9 e triazintiona 11. A dibenzoila 3 empregada foi obtida pela oxidação da benzoina na ausência de solvente em um estudo comparativo entre diferentes protocolos de oxidação, utilizando suportes sólidos associados ou não a energia de microondas com bons rendimentos sem empregar reagentes agressivos.
\end{abstract}

In this work, the reactivity of benzil was studied, employing $C, N$ - and $N, N$-nucleophiles, such as ethyl(3-amino substituted) 2-butenoates 4a-c, $(S, Z$ )-ethyl 3-(1-ethoxy-3-hydroxy-1-oxopropan2-ylamino)but-2-enoate $\mathbf{6}$, semicarbazide $\mathbf{8}$ or thiosemicarbazide $\mathbf{1 0}$, to evaluate their electrophilic centers as building blocks for the synthesis of the polyfunctionalized heterocyclic compounds, resulting in pyrrolinone 5a-c, pyrrole 7, triazinone 9 and triazinethione 11. The employed benzil 3 was obtained by the oxidation of the benzoin under solvent free conditions in a comparative study between different protocols of oxidation, using the methodology under mild reaction conditions and supported reagent associated to the microwave irradiation, with good results and without aggressive reagents.

Keywords: solid support, benzil, $N$-heterocycles

\section{Introduction}

The synthesis of heterocycles is becoming an important field of investigation in organic chemistry, being of interest not only to chemists, but also to biochemists and biologists, due to their wide-spread presence in nature. These compounds are known to participate in the metabolic pathway of live organisms, performing several biochemical functions and, consequently, are widely used. The literature describes that $60 \%$ of pharmaceuticals used in therapeutic systems are heterocycles and that $95 \%$ of those are $N$-functionalized. ${ }^{1}$

Our research group has been studying methodologies for the synthesis of heterocyclic systems using the reactions of 1,3-dielectrophiles, such as $\beta$-oxothioxo- $\alpha$ oxoketene- $O, N$-acetals, ethyl-2-chloro-acetoacetate and $\beta$-enamino carbonylic $\alpha$ and $\gamma$ functionalized with a series of dinucleophiles. ${ }^{2-6}$ The synthesis of these compounds has been successfully exploited through the methodology

\footnotetext{
*e-mail: mara@quimica.ufsm.br
}

of reaction in solid support using montmorillonita, $\mathrm{K}-10$, as a solid support associated to microwave energy or ultrasound sonication. These studies have provided different heterocyclic classes as pyrazoles, isoxazoles, 1,2-diazetine and triazin-3-one.

The literature describes the use of dielectrophiles such as glyoxal ( $\mathrm{HCOCOH}$ ) and phenyl glyoxal ( $\mathrm{HCOCOPh})$ with $\mathrm{C}, \mathrm{N}$-dinucleophiles to obtain heterocyclic compounds with pyrrolidine type. ${ }^{7,8}$ Considering the importance of the obtainment of new classes of $N$-heterocycles, in this work we have evaluated the reactivity of benzil $\mathbf{3}$ (1,2-diketone) with the nucleophiles $\beta$-enamino carbonyl ${ }^{9,10} \mathbf{4}$ and $\mathbf{6}$, semicarbazide $\mathbf{8}$ and thiosemicarbazide 10. The reactions were carried out in ethanol under reflux or microwave irradiation (MW) with solid support.

Benzil 3 was obtained from benzoin $\mathbf{2}$ in heterogeneous media, with the evaluation of different oxidative protocols using domestic microwave oven without solvents (Scheme 1). The use of the reactions under solvent free conditions with heterogeneous catalysts with or without microwave irradiation, is receiving special attention from organic 
chemistry because of the required reaction conditions, which conform the fundamental principles of green chemistry. ${ }^{9-12}$

\section{Experimental}

Melting points were determined with a Microquímica APF-301 apparatus and are uncorrected. ${ }^{1} \mathrm{H}$ and ${ }^{13} \mathrm{C}$ NMR spectra were recorded on a Bruker DPX 200 and DPX 400 spectrometer in deuteriochloroform / tetramethylsilane. Microwave irradiations were carried out in a Brastemp, model JET Defrost-27L domestic. The solid support K-10 (Fluka) was used. The mass spectra were registered on a GC/MS spectrometric system (HP 6890 GC connected to a HP 5973 and interfaced by a Pentium PC).

Oxidation of benzoin: procedure with claycop or clayfen under microwave irradiation

In a $100 \mathrm{~mL}$ beaker covered with watch glasses, benzoin $2(7 \mathrm{mmol})$ and $5 \mathrm{~g}$ of claycop or clayfen were mixed. The mixture was submitted to microwave irradiation at $500 \mathrm{~W}$ for $3 \mathrm{~min}$ when used claycop and at $300 \mathrm{~W}$ for $10 \mathrm{~min}$ when used clayfen. After irradiation by MW, the beaker with the reaction was cooled to room temperature. The products were extracted by washing the solid support with ethanol, filtered and the solvent was removed under vacuum. The product was recrystallized with $\mathrm{CCl}_{4}$ to give $\mathbf{3}$ (see Table 1).

Procedure with $\mathrm{KMnO}_{4} / \mathrm{CuSO}_{4} \cdot 5 \mathrm{H}_{2} \mathrm{O}$ under microwave irradiation

A powdered mixture of the oxidant was prepared by grinding $10 \mathrm{mmol}$ of $\mathrm{KMnO}_{4}$ with $10 \mathrm{mmol}$ of $\mathrm{CuSO}_{4} \cdot 5 \mathrm{H}_{2} \mathrm{O}$ until the complete homogenization. Benzoin 2 (1 mmol) and the oxidant mixture were placed in a closed glass container. The mixture was submitted to microwave irradiation at $300 \mathrm{~W}$ for $21 \mathrm{~min}$. The product was extracted by washing with dichloromethane. The organic layer was dried with $\mathrm{MgSO}_{4}$, filtered and the solvent was removed under vacuum. The product was recrystallized with $\mathrm{CCl}_{4}$ to give $\mathbf{3}$ (see Table 1).

\section{Procedure with $\mathrm{KMnO}_{4} / \mathrm{K}-10$ at room temperature}

Benzoin (1 mmol), potassium permanganate $(10 \mathrm{mmol})$ adsorbed in K-10 (0.3 g) and dichloromethane $(25 \mathrm{~mL})$ were vigorously stirred at room temperature for 44 hours. The mixture was vacuum filtered, dried with $\mathrm{MgSO}_{4}$, filtered and the solvent was removed under vacuum. The benzil was purified by recrystallization from $\mathrm{CCl}_{4}$ to give 3 (see Table 1).
Ehyl 2-methyl-5-oxo-4,4-diphenyl-4,5-dihydro-1H-pyrrole3-carboxylate 5a, ehyl 1-(benzyl)-2-methyl-5-oxo-4,4diphenyl-4,5-dihydro-1H-pyrrole-3-carboxylate $5 \boldsymbol{b}$ and ehyl 1-(2-ethoxy-2-oxoethyl)-2-methyl-5-oxo-4,4-diphenyl4,5-dihydro-1H-pyrrole-3-carboxylate $5 \mathrm{c}$

$M W / K-10:$ In a $100 \mathrm{~mL}$ beaker covered with watch glasses, benzil 3 (4 mmol) and ethyl 3-(amino substituted)-2butenoates $4 \mathbf{a}-\mathbf{c}(4 \mathrm{mmol})$ were dispersed on montmorillonita $\mathrm{K}-10$ (1.5 g). The heterogeneous mixture was submitted to microwave irradiation at $650 \mathrm{~W}$ for $7 \mathrm{~min}$. The product was extracted by washing the K-10 with ethyl acetate. The organic layer was washed with water, dried with $\mathrm{MgSO}_{4}$, filtered and the solvent was removed under vacuum to give 5. Compounds $\mathbf{5}$ were purified by column chromatography on silica gel (Vetec, 70-230 mesh) using petroleum etherEtOAc (15\%) as eluent, to give 5a (45\%), 5b (40\%) and 5c (20\%) with MS $m / z(\%) 407\left[\mathrm{M}^{+}\right]$(23), 362 (6), 334 (93), 260 (100).

Ehyl 1-(2-ethoxy-2-oxoethyl)-2-methyl-5-oxo-4,4diphenyl-4,5-dihydro-1H-pyrrole-3-carboxylate 5 and ethyl 1-(2-ethoxy-2-oxoethyl)-2-methyl-4,5-diphenyl-1Hpyrrole-3-carboxylate 7

Reflux/EtOH: Benzil 3 (4 mmol) and ethyl 3-(amino substituted)-2-butenoates 4a-c or (Z)-ethyl 3-(1-ethoxy-3hydroxy-1-oxopropan-2-ylamino)-but-2-enoate 6 (4 mmol) in ethanol $(8 \mathrm{~mL})$. The mixture was refluxed for $24 \mathrm{~h}$ to give 5a-c or 7. The solvent was removed under vacuum. These were extracted with ethyl acetate, then the organic layer was washed with water $(3 \times 10 \mathrm{~mL})$, dried over magnesium sulfate, filtred and the solvent was removed in vacuum to yield to crude pruduct. Products 5a-c or $\mathbf{7}$ were purified by column chromatography on silica gel (Vetec 70-230 mesh) using $15 \%$ petroleum ether and ethyl acetate as eluent.

\section{5,6-Diphenyl-2,3,-dihydro-1,2,4-triazine-3-one 9 and 5,6-diphenyl-2,3-dihydro-1,2,4-triazine-3-tione 11}

$M W / K-10$ : Benzil 3 (0.25 mmol) and semicarbazide 8 (0.50 mmol) or thiosemicarbazide $\mathbf{1 0}(0.50 \mathrm{mmol})$ were dispersed on K-10 (0.07 g). The heterogeneous mixture was submitted to microwave irradiation at $500 \mathrm{~W}$ for the time described in Scheme 3. The products were extracted by washing the K-10 with dichloromethane. The organic layer was washed with water, dried with $\mathrm{MgSO}_{4}$, filtred and the solvent was removed vacuum to give $\mathbf{9}$ and $\mathbf{1 1}$.

Reflux/EtOH: Benzil 3 (0.5 mmol) was mixed with semicarbazide $\mathbf{8}(1 \mathrm{mmol})$ or thiosemicarbazide $\mathbf{1 0}$ 
( $1 \mathrm{mmol}$ ) in ethanol. The mixture was refluxed for $24 \mathrm{~h}$ for give 9, 36 hours for give 11. The solvent was removed under vacuum. These were extracted with dichloromethane, then the organic layer was washed with water $(3 \times 10 \mathrm{~mL})$, dried over magnesium sulfate, filtered and the solvent was removed in vacuum to yield the crude products. Was obtained the product $\mathbf{9}(76 \%)$ and $\mathbf{1 1}(74 \%)$ were purified by column chromatography on silica gel (Vetec, 70-230 mesh) using dichloromethane as eluent.

\section{Results and Discussion}

The study of different oxidative protocols to obtain benzil from benzoin $\mathbf{2}$ with microwave and solvent free conditions was carried out in the work because the procedures described in the literature for these oxidation, generally use harsh reaction conditions.

The simplest way to oxidize aromatic molecules on a solid support is by the action of transition metals cations or induced in silicates. The most used systems are supported reagents such as Clayfen $\left(\mathrm{K}-10 / \mathrm{Fe}\left(\mathrm{NO}_{3}\right)_{3}\right)$ or Claycop $\left(\mathrm{K}-10 / \mathrm{Cu}\left(\mathrm{NO}_{3}\right)_{2} \cdot{ }^{13,14}\right.$ In this work we made a comparative study of the oxidation reactions to the formation of benzil 3. The strategy to obtain $\mathbf{3}$, involves the condensation of benzaldehyde 1 with potassium cyanide ${ }^{15,16}$ to obtain the benzoin 2 that was submitted the oxidation (Scheme 1).

Among the different methodologies used to the benzoin oxidation (Table 1), we used reactions on solid supports, such as $\mathrm{CuSO}_{4} \cdot 5 \mathrm{H}_{2} \mathrm{O}$ and $\mathrm{K}-10$ doped with the oxidizing agents $\mathrm{KMnO}_{4}, \mathrm{Fe}\left(\mathrm{NO}_{3}\right)_{3}$ and $\mathrm{Cu}\left(\mathrm{NO}_{3}\right)_{2}$ without solvent and with microwave irradiation (MW). To validate these methodologies, we compared the methods described in the literature for benzoin oxidation ${ }^{18,19}$ with the methods developed here using reactions in homogeneous media with and without reflux.
The use of solvent free conditions with heterogeneous media in microwave demonstrated greater efficiency and much reduced reaction time when compared with methods in homogeneous media.

As part of our program related to the study of the synthesis of heterocyclic from enamino carbonylic compounds, we report in this work the reactions of benzil 3 with $\alpha, \beta$-unsaturated ester $\mathbf{4 a - c}$ and $\alpha, \beta$-unsaturated ester 6 (Scheme 2). The reaction of benzil with the $\beta$-enamino carbonylic $\mathbf{4 a - b}$ and glycine derivative $\mathbf{4 c}$, was performed with two different reactions conditions: refluxing in ethanol for $24 \mathrm{~h}$; and microwave irradiation (MW) for 7 min using solid support, montmorillonite, K-10, without solvent. For both reaction conditions, pyrrolinone $\mathbf{5 a}, \mathbf{5 b}$ and $\mathbf{5 c}$ were isolated with a yield of 45 , 40 and $20 \%$ respectively. To the best of our knowledge, this is a new heterocyclic compound. The method using solid support and MW shows a great reduction in the reaction time. The structure of the product obtained indicates that an 1,2- migration occurs.

This low yield is due to the degradation or descarboxylation of dinucleophile $\mathbf{4 c}$, as observed in the analysis of the ${ }^{1} \mathrm{H}$ NMR spectra during the purification process in which it was possible to identify the presence of ethyl acetoacetate and aminoester derived from glycine. The reaction was further evaluated using a solid support with microwave irradiation, obtaining the heterocyclic 5, and also, observing the decomposition of the dinucleophile $\mathbf{4 c}$.

In this reaction we observed first the nucleophilic attack of the $\alpha$ carbon of $\mathbf{4}$ to one of the carbonylic carbons of the dielectrophile benzil $\mathbf{3}$ followed of cyclization with the attack of the nitrogen atom of dinucleophile 4 to the other carbonylic carbon of compound $\mathbf{3}$. The final product $\mathbf{5}$ was obtained through the 1,2 migration of the phenyl group, which is a benzylic type rearrangement, ${ }^{16}$ that is similar to<smiles>C[14CH2]c1ccc(C(=O)c2ccccc2)cc1</smiles>

Scheme 1. Reaction conditions a) KCN/ethanol/reflux and b) see Table 1.

Table 1. Oxidation methodologies

\begin{tabular}{lccccc}
\hline Conditions & $\begin{array}{c}\mathrm{CuSO}_{4} \cdot 5 \mathrm{H}_{2} \mathrm{O} \\
\mathrm{Py}_{2} \mathrm{H}_{2} \mathrm{O} / \mathrm{rt}^{19}\end{array}$ & $\begin{array}{c}\mathrm{MnO}_{2} \\
\mathrm{~K}-10 / \mathrm{rt}^{18}\end{array}$ & $\begin{array}{c}\mathrm{KMnO}_{4} \\
\mathrm{~K}-10 / \mathrm{rt}\end{array}$ & $\begin{array}{c}\mathrm{MW} / 300 \mathrm{~W} \\
\mathrm{KMnO}_{4} / \mathrm{CuSO}_{4} \cdot 5 \mathrm{H}_{2} \mathrm{O}\end{array}$ & $\begin{array}{c}\mathrm{MW} / 300 \mathrm{~W} \\
\mathrm{Clayfen}\end{array}$ \\
\hline Time & $2 \mathrm{~h}$ & $21 \mathrm{~h}$ & $44 \mathrm{~h}$ & $21 \mathrm{~min}$ & $3 \mathrm{~min}$ \\
Yield $\%$ & 83 & 64 & 87 & 70 & $900 \mathrm{~min}$ \\
\hline
\end{tabular}


the Biltz synthesis to obtain phenytoin. ${ }^{17,23}$ Biltz reported that the reaction of $N$-methylurea with benzil resulted in formation of 5,5-diphenylhydantoin.
The reaction of benzil with the serine derivative $\mathbf{6}$ afforded ethyl 1-(2-ethoxy-2-oxoethyl)-2-methyl-4,5diphenyl- $1 H$-pyrrole-3-carboxylate system 7 via a different

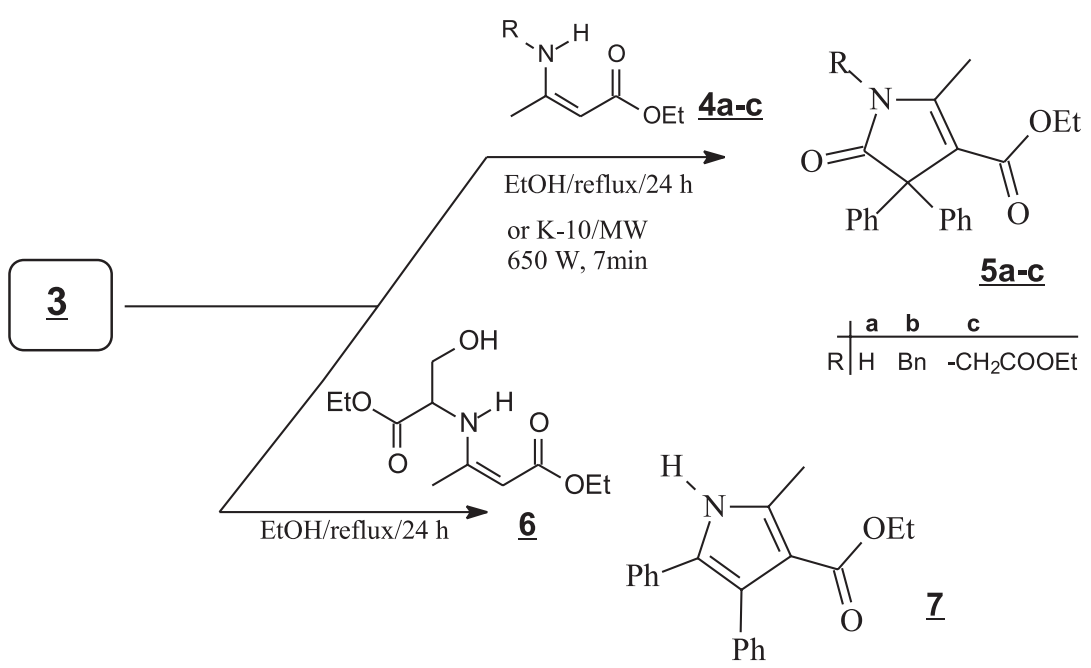

Scheme 2. Route to obtain pyrrolinone and pyrrole systems.

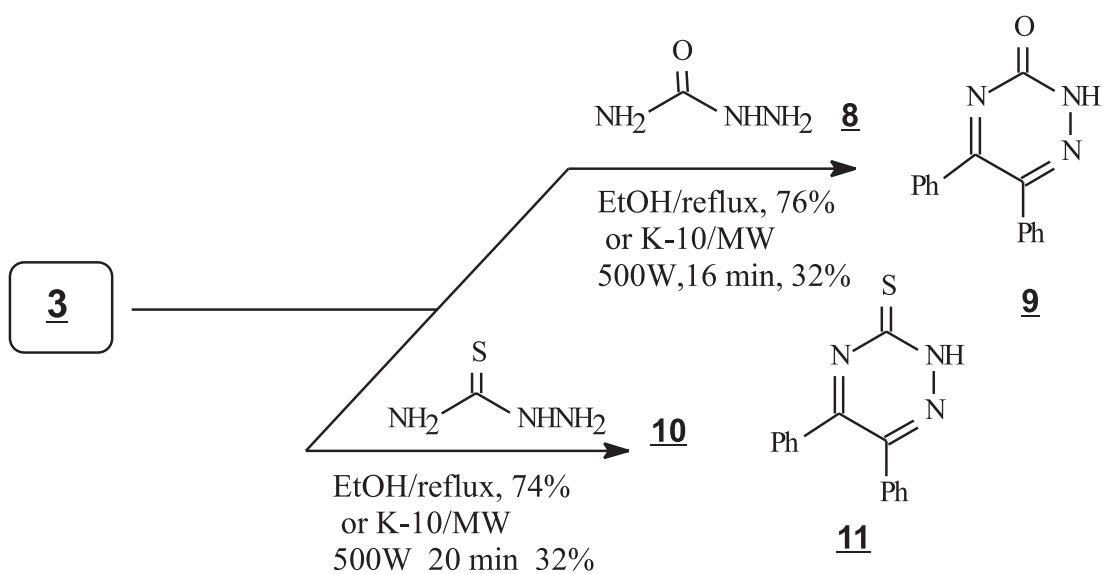

Scheme 3. Route to obtain triazinone and triazinethione systems.

Table 2. Functionalized $N$-heterocycles 5a-c, 7, 9 and 11 prepared

\begin{tabular}{|c|c|c|}
\hline Product & $\begin{array}{c}{ }^{1} \mathrm{H} \mathrm{NMR}\left(\mathrm{CDCl}_{3} / \mathrm{TMS}\right) \\
\delta, J(\mathrm{~Hz})\end{array}$ & $\begin{array}{c}{ }^{13} \mathrm{C} \mathrm{NMR}\left(\mathrm{CDCl}_{3} / \mathrm{TMS}\right) \\
\delta, J(\mathrm{~Hz})\end{array}$ \\
\hline $5 \mathbf{a}$ & $\begin{array}{l}1.30(\mathrm{t}, 3 \mathrm{H}, J 7.1), 2.03(\mathrm{~s}, 3 \mathrm{H}), 4.19(\mathrm{q}, 2 \mathrm{H}, J 7.1) \\
7.10-7.28(\mathrm{~m}, 10 \mathrm{H}, 2 \mathrm{Ph}), 8.24(\mathrm{sl}, 1 \mathrm{H}, \mathrm{NH})\end{array}$ & $\begin{array}{l}12.60,16.2,40.70,60.61,113.82,126.3,128.2,129.3,133.8,138.21, \\
167.3,188.9\end{array}$ \\
\hline $5 \mathbf{b}$ & $\begin{array}{l}1.28(\mathrm{t}, 3 \mathrm{H}, J 7.2), 2.21(\mathrm{~s}, 3 \mathrm{H}), 4.18(\mathrm{q}, 2 \mathrm{H}, J 7.2), 4,46 \\
(\mathrm{~s}, 2 \mathrm{H}), 7.06-7.31(\mathrm{~m}, 15 \mathrm{H}, 3 \mathrm{Ph})\end{array}$ & $\begin{array}{l}14.25,15.90,46.21,59.90,61.72,126.9,128.62,129.3,133.84 \\
141.65,156.10,167.20,165.83\end{array}$ \\
\hline $5 c$ & $\begin{array}{l}1.09(\mathrm{t}, 3 \mathrm{H}, J 7.1), 1.30(\mathrm{t}, 3 \mathrm{H}, J 7.1), 2.54(\mathrm{~s}, 3 \mathrm{H}), 4.00 \\
(\mathrm{q}, 2 \mathrm{H}, J 7.1), 4.26(\mathrm{q}, 2 \mathrm{H}, J 7.1), 4.35(\mathrm{~s}, 2 \mathrm{H}), 7.20-7.40 \\
(\mathrm{~m}, 10 \mathrm{H}, 2 \mathrm{Ph})\end{array}$ & $\begin{array}{l}12.51,13.89,14.06,41.57,59.57,62.07,63.45,113.79,127.25 \\
127.79,129.14,139.76,152.93,163.87,167.79,179.75\end{array}$ \\
\hline 7 & $\begin{array}{l}1.01(\mathrm{t}, 3 \mathrm{H}, J 7.0), 2.60(\mathrm{~s}, 3 \mathrm{H}), 4.07(\mathrm{q}, 2 \mathrm{H}, J 7.0) \\
7.06-7.26(\mathrm{~m}, 10 \mathrm{H}, 2 \mathrm{Ph}), 8.46(\mathrm{sl}, 1 \mathrm{H}, \mathrm{NH})\end{array}$ & $\begin{array}{l}13.78,13.87,59.16,112.66,123.40,127.27,126.49,127.24,127.53, \\
128.43,130.77,132.20,135.40,136.10,165.61\end{array}$ \\
\hline 9 & $1.20-1.32(\mathrm{br}, 1 \mathrm{H}, \mathrm{NH}), 7.15-7.82(\mathrm{~m}, 10 \mathrm{H})$ & $\begin{array}{l}127.76,128.01,128.45,128.88,129.46,131.16,133.55,134.71, \\
143.12,154.57,167.70\end{array}$ \\
\hline 11 & $2.00-2.40(\mathrm{br}, 1 \mathrm{H}, \mathrm{NH}), 7.20-7.60(\mathrm{~m}, 10 \mathrm{H})$ & $\begin{array}{l}128.45,128.57,128.79,129.29,129.78,131.13,134.60,134.70, \\
155.2,155.9,167.65\end{array}$ \\
\hline
\end{tabular}


cyclization pathway (see Scheme 2). The heterocyclic 7 was identified by ${ }^{1} \mathrm{H}$ and ${ }^{13} \mathrm{C}$ NMR spectroscopy and confirmed with the literature described where 7 was obtained by the reaction of enaminone and ketocarbene. ${ }^{20}$

We investigated the reactivity of benzil 3 using $N, N$-dinucleophiles to evaluate the regiochemistry in the formation of 5 or 6 membered rings. The compound triazin-3-one 9 was obtained with $32 \%$ of yield when semicarbazide $\mathbf{8}$ was used and triazin-3-thione $\mathbf{1 1}$ was obtained using thiosemicarbazide 10. These compounds were analyzed by NMR and, in both cases, in the synthesis of 9 and 11, phenyl group migration was not observed in contrast to that of $\mathbf{5}$ a-c.

These reactions were accomplished using a domestic microwave oven without solvent and with time and power according to Scheme 3. A stoichiometric excess of the dinucleophiles was used. When these reactions were accomplished in homogeneous media using EtOH/reflux, better yields were achieved, $76 \%$ to compound 9 and $74 \%$ to compound $\mathbf{1 1}$.

\section{Conclusions}

The results achieved demonstrate the versatility of the benzil system to synthesize heterocycles, using reactions on solid supports with microwave irradiation. The synthesis of benzil, previously done with harsh reaction conditions, was successful accomplished without aggressive reagents on solid support, such as Claycop or Clayfen, with microwave irradiation, giving the product in good yields.

This results showed that the formation of the heterocyclic compounds 5a-c and $\mathbf{7}$ starting from benzil and enamine derivatives occurs through different reaction pathways. For 4a-c, the benzil-benzilic migration was observed. However, when serine derivative 7 was used the migration was not observed. With the semicarbazide type dinucleophiles, we obtained the triazine as a result of the direct condensation with the terminal nitrogen of the system. In this case, the use of K-10/MW afforded $\mathbf{9}$ and $\mathbf{1 1}$ with low yield, however, of reaction time decreases significantly and gives a rapid access to triazinones when compared with traditional methods. $^{21,22}$

\section{Acknowledgments}

We are grateful to Coordenação de Aperfeiçoamento de Pessoal de Nível Superior (CAPES), Brazil and Conselho Nacional de Desenvolvimento Científico e Tecnológico (CNPq-PIBIC) fellowships to C.C.C and M.S respectively.

\section{References}

1. Menegatti, R.; Manssour, C. A.; Barreiro, E. J.; Quim. Nova 2001, 3, 16.

2. Braibante, M. E. F.; Braibante, H. S.; Valduga, C.; J. Heterocycl. Chem. 1997, 34, 1453.

3. Braibante, M. E. F.; Braibante, H. S.; Missio, L.; J. Heterocycl. Chem. 1996, 33, 1243.

4. Oriques, D. A.; Ph.D Thesis, Universidade Federal de Santa Maria, Brasil, 2005.

5. Braibante, M. E. F.; Braibante, H. S.; Roza, J. K.; Henriques, D. M.; Tavares, L. C.; Synthesis 2003, 1160.

6. Braibante, M. E. F.; Braibante, H. S.; Tavares, L. C; Rothe, S. F.; Costa, C. C.; Morel, A. F.; Stiker, C. Z.; Burrow, R. A.; Synthesis 2007, 2485.

7. Caballero, E.; Puebla, P.; Domercq, M.; Medarde, M.; Lopez, J. L.; San Feliciano, A; Tetrahedron 1994, 50, 7849.

8. Agami, C.; Beauseigneur, A.; Comesse, S.; Dechoux, L.; Tetrahedron Lett. 2003, 44, 7667.

9. Braibante, M. E. F.; Braibante, H. T. S.; Morel, A. F.; Costa, C. C; Lima, M. G.; J. Braz. Chem. Soc. 2006, 17, 184.

10. Braibante, H. T. S.; Braibante, M. E. F.; Rosso, G. B.; Oriques, D. A.; J. Braz. Chem. Soc. 2003, 14, 994.

11. Lidström, P.; Tierney, J.; Wathey, B.; Westman, J.; Tetrahedron 2001, 57, 9225.

12. Sanseverino, A. M.; Quim. Nova. 2000, 23, 102.

13. Varma, R. S.; Dahiya, R.; Tetrahedron Lett. 1998, 39, 1307.

14. Cornelis, A.; Laszlo, P.; Synthesis 1980, 849.

15. Bhattacharya, A.; Purohit, V. C.; Belle, N. R.; J. Chem. Educ. 2004, 81, 1020.

16. Soares, B. G.; Souza, N. A; Píeres, D. Química Orgânica Teoria e Técnicas de Preparação, Purificação e Identificação de Compostos Orgânicos, Editora Guanabara S.A.: Rio de Janeiro, 1988.

17. Muccioli, G.; Poupaert, J. H.; Wouters, J.; Norberg, B.; Poppitz, W.; Scriba, G. K. E.; Lambert, D. M.; Tetrahedron 1998, 59, 1301.

18. Ault, A.; Techniques and Experiments for Organic Chemistry, University Science: Sausalito, California, 1998.

19. Crouch, R. D.; Holden, M. S.; Burger, J. S.; J. Chem. Educ. 2001, 78, 951.

20. Eberlin, M. N.; Kascheres, C.; J. Org. Chem. 1988, 53, 2084.

21. Gummerus, G. R; Comment. Phys. Math. 1966, 32, 5.

22. Polonovski, M.; Pesson, M.; Compt. Rend. 1951, 232, 1260.

23. Butler, R. A.; Leitch, E.; J. Chem. Soc. Perkin II 1977, 1972.

Received: August 20, 2007

Web Release Date: April 23, 2008 